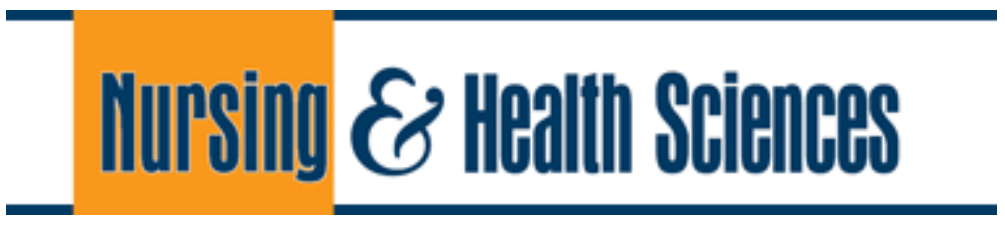

\title{
Quality of Life and associated factors in siblings of children with severe motor and intellectual disabilities: A cross- sectional study
}

\begin{tabular}{|r|l|}
\hline Journal: & Nursing and Health Sciences \\
\hline Manuscript ID & NHS-0646-2018.R5 \\
\hline Manuscript Type: & Research Article \\
\hline Keywords: & $\begin{array}{l}\text { Family, Quality of Life, Siblings, Empowerment, Children with disabilities, } \\
\text { Japan }\end{array}$ \\
\hline \multicolumn{2}{|l}{} \\
\hline
\end{tabular}

\section{SCHOLARONE \\ Manuscripts}




\begin{abstract}
(176 words)
\end{abstract}
This study examined quality of life and its associated factors in siblings of children with severe motor and intellectual disabilities in Japan. The participants were 789 siblings of children with a disability and their primary caregivers. We used the Kinder Lebensqualität Fragebogen questionnaire to assess the quality of life of siblings. The mean age of the siblings in this study was $12.21 \pm 3.07$ years, and the mean quality of life score was $69.63 \pm 12.55$ points, which is higher than that of the general population of children of the same age. It was revealed that the following factors contributed to higher quality of life scores: a closer relationship with the child with a disability, younger age, the primary caregiver's lower care burden, later birth order of siblings (i.e., younger siblings), higher family empowerment, and female gender of siblings. The relationship with the child with a disability had the strongest influence on siblings' quality of life. Our study suggests the need for nursing interventions that focus on the whole family to enhance siblings' quality of life.

Keywords: Children with disabilities, Family, Empowerment, Japan, Quality of life, Siblings 


\section{INTRODUCTION}

Families caring children with disabilities are faced with several challenges in family life. In particular, regarding the experiences of the families of children with chronic conditions, it has also been reported that the siblings are socially resilient yet overlooked members of the family who may present psychological, academic, and peer-related difficulties following the diagnosis of a brother or sister with chronic conditions (Gan, Lum, Wakefield, Nandakumar, \& Fardell, 2016). Orsmond and Seltzer (2017) provide some evidence that the siblings of children with autism spectrum disorders describe both positive and negative aspects of their sibling relationship and may be at an increased risk of social and behavioral adjustment problems during childhood and adolescence. In addition, the siblings of children with a disability have reported close relations within their families due to the potential role shifts of family members in their situation (Van Riper, 2003). Moreover, siblings of these children have feeling of forbearance (Moyson\& Roeyers, 2011). The forbearance leads to difficulty in expressing their feelings.

The influence of children with disabilities on their siblings is modified by several factors relating to the characteristics and dynamics of the individual family members and of the family as a whole. Living with a child with disability is thus hypothesized to have a significant impact on the quality of life (QoL) of their siblings. QoL pertains to psychological well-being, social relationships, physical functions, and activities of daily life as perceived by both adults and children (Ravens-Sieberer \& 
Bullinger, 1998).

The number of severe motor and intellectual disabilities (SMID) is increasing in Japan, with the current number estimated to be about 40,000. Children with SMID have been defined as "children with severe physical and intellectual disability." This term is included in the Children with Special Healthcare Needs (CSHCN) (McPherson et al., 1998). These children require very high-level specialist medical care, such as respiratory support, nutritional support, and daily rehabilitation. The most common diagnoses in SMID are cerebral palsy and chromosomal abnormalities. About $70 \%$ of children with SMID live at home (Okada, Iai, Ishii, \& Ozawa, 2015). Children with SMID require constant long-term care, as they cannot move on their own to perform most of the activities of daily living and have difficulty in engaging in verbal communication (Tokyo Metropolis, 2014). The family caregivers of children with CSHCN and SMID has impacted from their daily caregiving. There is evidence that caring for these children affects the family caregivers' physical and mental health (Davis \& Gavidia-Payne, 2009; Raina et al., 2005), friendships, marital lives, social participation (Davey et al., 2015), and employment (Okumura et al., 2009), as well as the economic situation of the whole family (Davis et al., 2010; Ushio, 2014). Support for the lives of families of children with SMID was instituted by law in 1967 through institutional services for children with SMID in Japan. Today, there are many kinds of social services, such as short-stay services, visiting nurses, helpers, and day care services. It is still, however, necessary to consider support for these families in the effective use of 
such services to increase their quality of life (Nishigaki et al., 2016).

Quality of life (QoL) is a psychological concept describing the physical, social, psychological, and functional aspects of well-being, therefore, support to improve the QOL of siblings of the families raising these children is essential. Especially, Bertelli et al. (2011) described that the QoL is perceived somewhat differently by individuals and by members of their families. Recent research on sibling quality of life has, however, found a discrepancy between parents' and siblings' reports (Houtzager, 2005). Most research on sibling adjustment is based on parental report. Therefore, when planning the care for the siblings, it is important to take into consideration their own self-reported QoL.

\subsection{Literature review}

Previous studies have reported inconsistent results on QoL of siblings of children with a disorder or illness. Some studies have reported the significant impairment of the QoL of siblings of children with a chronic illness compared to siblings of healthy children (Eladl \& Atwa, 2011; Rana \& Mishra, 2015; Y1lmaz, Türkeli, Karaca, \& Yüksel, 2017). On the other hand, other studies have reported comparatively high QoL among siblings of children with diseases such as cystic fibrosis and leukemia (Berbis et al., 2015; Havermans et al., 2011). Based on a systematic review, Limbers and Skipper (2014) found that the higher the severity of the disease in children with a chronic health condition such as cancer, type 1 diabetes, or epilepsy, the higher the risk of a decline in their siblings' QoL. It is 
therefore hypothesized that the QoL of siblings of children with SMID is lower than that of siblings

of healthy children.

Another study reported that illness-related problem behavior and female gender were negatively correlated with QoL of siblings of children with psychological disorders (Bowman, Alvarez-Jimenez, Wade, Howie, \& McGorry, 2014). Furthermore, among siblings of children with leukemia, Berbis et al. (2015) found that an older age at diagnosis for both siblings and children with leukemia, low socioeconomic status, and cancer-related factors were risk factors for impaired QoL of siblings. Furthermore, Barrera, Atenafu, Nathan, Schulte, and Hancock (2018) developed an intervention program for siblings of children with cancer, and assessed its efficacy in addressing depression symptoms and QoL of siblings, but their results were inconclusive. In addition, no previous study has reported on QoL of siblings of children with SMID, which may be presumed to be much lower than in siblings of healthy children.

To understand the experiences and perceived needs of siblings of children with SMID and to develop support programs, we should focus on siblings' QoL via their own voice by directly asking them for their perspectives (Meadan, Stoner, \& Angell, 2010). Previous studies reported differences between parent-reported and sibling-reported QoL. With respect to assessing the QoL of siblings of children with a disorder or illness, previous research revealed significant discrepancies between the siblings' self-reports and their parent-proxy reports (Baca, Vickrey, Hays, Vassar, \& Berg, 2010; Houtzager, 
Grootenhuis, Caron, \& Last, 2005), especially on social and emotional subscales (Schulte, Wurz,

Reynolds, Strother, \& Dewey, 2016).

\subsection{Framework}

As mentioned above, the QoL of siblings is largely influenced by the functions and empowerment of the whole family and factors relating to their parents (marital status, working style, physical status, psychological status, and so forth) who raise and take care of them. Moreover, the situation of the parents also affects the QoL of siblings. In particular, since primary caregivers spend a significant amount of time with the siblings, the primary caregivers' physical and psychological situation must be assessed in order to consider the QoL of siblings. In this study, we set variables and scales in order to explore the QoL of siblings in an exploratory manner, mainly in relation to the assumed factors of families and parents.

\subsection{Purpose}

The purposes of this study were to clarify the self-reported QoL of siblings of children with SMID and its associated factors with a focus on family environmental factors, such as the QoL of caregivers, family empowerment, and family functioning, and to devise both appropriate and comprehensive forms of support for the entire family with vulnerabilities and practical approaches to improve siblings' 
QoL.

\section{METHODS}

\subsection{Design}

This study was conducted in Japan using a self-report questionnaire-based, cross-sectional design.

\subsection{Participants and settings}

We recruited siblings aged 6-18 and the primary caregivers of children with SMID who attend special needs schools in Japan. The inclusion criteria included being able to read and write in Japanese.

\subsection{Data collection}

We phoned all 212 special needs schools that span the entire younger-to-older age ranges (6-18 years old) in Japan, of which 89 agreed to participate in this study. They sent out questionnaires to every family at their school. We contacted the primary caregivers of children with SMID and provided the consent form and questionnaires via the schoolteachers. We recruited primary caregivers, partners of primary caregivers, and siblings of children with SMID. If a child with SMID attending the above schools had siblings between the ages of 6-18 years, they were included in the study. It was clarified in the manual that if there were multiple siblings per child with SMID to be included, only the sibling 
who had cohabitated the longest with the child with SMID would be selected. Siblings with disabilities and siblings living separately from the child with SMID were excluded from this study. This means that we excluded infants, toddlers, and siblings that lived away from home, and if the sibling was affected by their own disability or an even more severe SMID than the index child, they were also excluded. We included both adopted and fostered siblings if they lived with the children with SMID as a family. Each family placed their completed questionnaires in an envelope and submitted them at their child's school, which then sent the collected envelopes to the researchers' institution. Data were collected between November 2015 and March 2016.

\subsection{Measurement tools}

Siblings of children with SMID answered the following two questionnaires: one on the attributes of the siblings, the Kinder Lebensqualität Fragebogen (KINDL), and one on their relationship with the child with SMID. Primary caregivers answered the following questionnaires: Attributes of Primary Caregivers, Family and Children with SMID, the Japanese version of the Family Empowerment Scale (J-FES), the Eight-Item Short Form of the Japanese version of the Zarit Burden Interview (J-ZBI_8), the Family Adaptability and Cohesion Evaluation Scale Kwansei Gakuin IV-16 (FACESKGIV-16), and the Eight-Item Short Form Health Survey (SF-8). In using these scales for families of child with SMID, we verified the content validity of all of them. We then surveyed the results of the KINDL, J- 
FES, J-ZBI_8, FACESKGIV-16, and SF-8 and obtained permission to use these scales.

\subsubsection{QoL of siblings}

The KINDL assesses health-related QoL in children and adolescents (Ravens-Sieberer \& Bullinger, 1998). It has been translated into 30 languages and has been used in many international studies. Matsuzaki et al. (2007) and Shibata et al. (2003) translated and developed a Japanese version of the KINDL comprised of 24 items that yield a general QoL score and scores for the following six subscales: physical health, general health, family functioning, self-esteem, social functioning, and school functioning. Siblings with at least one chronic condition answered the disease module, consisting of six items. Each item is scored using a five-point Likert scale. Total scores and subscales are transformed into a range of 0-100, with higher scores indicating better QoL. In this study, we adopted different measurement batteries for siblings from KINDL, because it does not measure all objects with the same battery; it is recommended to use a corresponding battery according to the year range. The Cronbach's $\alpha$ was .83-.85, and thus internal consistency was confirmed in this study.

\subsubsection{Relationship between children with SMID and their siblings}

The relationship between children with SMID and their siblings was assessed with the following three items rated on a five-point Likert scale $(1=$ never to $5=$ all the time $)$. Item 1 asked participants 
to respond to the statement "I have a good relationship with my sisters or brothers," Item 2 was "I take care of my sisters or brothers," and Item 3 was "I enjoy taking care of my sisters or brothers." The items were developed by the authors based on the findings of a previous study (Wakimizu, Fujioka, Numaguchi, Nishigaki, \& Sato, 2015) and validated carefully so that even young children could understand and answer them. A higher score indicated that siblings had a favorable opinion of their relationships with their siblings. The Cronbach's $\alpha$ for this scale was .79 in this study.

\subsubsection{Attributes of children with SMID}

For the attributes of children with SMID, primary caregivers reported on the presence and type of medical care. We modified the severity assessment tool developed by Suzuki et al. (2008) to make it easier for primary caregivers to understand. Examples of questions are as follows: "What care does your child need for breathing? Check all the following applicable cares. a. Ventilator (10 points), b. Tracheostomy ( 8 points), c. Airway (5 points), d. Oxygen inhalation (5 points), e. Suction at least once per hour (8 points), f. Suction more than six times a day (3 points)." This tool required simplification to ensure consistency in the answers by primary caregivers without specialized medical knowledge. Children scoring more than 25 points on this scale were classified as being in the SMID-medical care dependent group (SMID-MCDG), and those scoring 10-25 points were classified as sub-SMIDMCDG. This classification is the most valuable tool to assess the need for social services in Japan. 


\subsubsection{Primary caregivers' burden}

The J-ZBI_8 is an instrument for measuring a caregiver's perceived burden of providing family care (Arai, Tamiya, \& Yano, 2003); its reliability and validity have been verified. The J-ZBI has high internal consistency $($ Cronbach's alpha $=0.89)$. Items are rated on a five-point scale ranging from $0=$ never to $4=$ nearly always, and the total score ranges from 0 to 32 . A higher score indicates a higher caregiver burden. For primary caregivers of children with SMID, the care-related burden is an essential component of continued home care (Dambi et al., 2016). This scale is suited to assessing the carerelated burden of primary caregivers of patients in various situations.

\subsubsection{QoL of primary family caregivers}

The SF-8, whose reliability and validity have been verified, was developed to evaluate the general aspects of health-related QoL (Tokuda et al., 2009). It consists of eight items that provide two summary scores: a physical health component summary (PCS) and a mental health component summary (MCS). A higher score indicates higher QoL.

\subsubsection{Family functioning}

The FACESKGIV-16, whose reliability and validity have been verified, is an instrument for assessing 
families (Ikeno et al., 1990). The FACESKGIV-16 has high internal consistency (Cronbach's alpha= 0.71-0.99). In this instrument, family functioning is evaluated through a combination of two dimensions: adaptability and cohesion. A balanced level of cohesion and adaptability indicates a functional family. The FACESKGIV-16 measures the function and relationships of each family member (Ikeno et al., 1990). Since the siblings of children with SMID need family care to continue their daily lives, the family relationships of siblings of children with SMID are very important.

\subsubsection{Family empowerment}

Koren, DeChillo, and Friesen (1992) define family empowerment as "the state or ability of families to cooperate with elements outside of their living scope by controlling their life for the purpose of raising a child with severe disabilities." It can be assessed using their Family Empowerment Scale. The reliability and validity of the Japanese version of this scale were confirmed by Wakimizu, Fujioka, Furuya, Iejima, and Yoneyama (2010).

The J-FES consists of the following three equally important domains: family, service system, and social/political. The family domain represents the ability of family caregivers to raise children with SMID by themselves. The service system domain represents awareness of social services to assist with childrearing. The social/political domain represents the capability to encourage social action and change for the sake of other children with SMID. The J-FES consists of 34 items across the 
abovementioned three subscales, e.g., "I make an effort to learn new methods to help my children grow and develop," "I can work together with administrative bodies and experts, doctors, visiting nurses, and public health nurses to decide what service my children need," and "I contact legislators when important bills or issues regarding my children are left unresolved." Each item is scored using a five-point Likert scale. Higher scores indicate higher family empowerment. We used only the subscale scores for our analysis, not the total score of the J-FES. The J-FES is used to address problems relating to family empowerment (Wakimizu et al., 2010).

\subsection{Data analysis}

SPSS version 24.0 for Windows was used for data analysis. Descriptive statistics were computed for the sample attributes and scores on the instruments. We then conducted a logistic regression analysis to reveal related factors of siblings' QoL. Before we performed the multiple regression analysis, the Spearman's rank correlation coefficient was calculated to select the variables relevant to the $\mathrm{KINDL}^{\mathrm{R}}$ scores. Statistically significant variables were used to perform a stepwise multiple regression analysis to identify the predictors of QoL. In the multiple regression, the variance inflation factor was used as an indicator of multicollinearity. The level of statistical significance was set at $p<.05$.

\subsection{Ethical considerations}


Teachers distributed the description of the purpose, method, and ethical considerations of this study

to the parents of children with a disability. Only participants who gave their consent answered the questionnaire. The questionnaires were anonymous and returned in individual envelopes. We also explained that participation was voluntary and that there would be no disadvantage arising from refusal to participate or cancellation after providing written consent. This study was approved by the Institutional Review Board of T University (Approval No. 1004).

\section{RESULTS}

A total of 1,659 (a participation rate of 35.2\%) out of 4,707 families from 89 special needs schools in Japan answered our questionnaires. Siblings outside the age criteria and those who did not answer the entire $\mathrm{KINDL}^{\mathrm{R}}$ were excluded; thus, only the data collected from 789 siblings of children with SMID and their primary caregivers were used for our analysis.

Table 1 shows the attributes of the sample. The mean age of the siblings was $12.21 \pm 3.07$ years; $419(53.1 \%)$ of them were 6-12 years old, and 361 (45.8\%) were 13-18 years old. In total, 84 siblings had at least one chronic condition. About $70 \%$ of the primary caregivers were 30-39 years old and $93.2 \%$ were married. Over $50 \%$ of the primary caregivers were unemployed. Disabilities in most children with SMID were caused by cerebral palsy, periventricular leukomalacia, or chromosomal aberration. Regarding the severity scores of children with SMID, 187 (23.7\%) were classified as sub- 
SMID-MCDG, and $63(8.0 \%)$ were classified as SMID-MCDG.

Table 2 shows the scores for the KINDL ${ }^{\mathrm{R}}$ (which reports the QoL of siblings of children with SMID), the relationship with children with SMID, the primary caregiver's burden (J-ZBI_8), family empowerment (J-FES), family function (FACESKGIV-16), and the QoL of the primary family caregivers (SF-8). The affective well-being dimension showed the highest scores, and the self-esteem dimension the lowest scores for the QoL of siblings of children with SMID (KINDL ${ }^{\mathrm{R}}$ ). Regarding the relationship with children with SMID, for the item "I have a good relationship with my siblings," $72.7 \%$ of the respondents answered "often" or "all the time." The mean total score for family empowerment (J-FES) was $101.05 \pm 17.11$ points.

Table 3 shows the correlations for the QoL of siblings of children with SMID (KINDL ${ }^{\mathrm{R}}$ ) scores, the attributes of the sample, the primary caregiver's burden (J-ZBI_8), the family empowerment score (JFES), the family functioning score (FACESKGIV-16), and the QoL of the primary family caregiver score (SF-8). Gender $(r=.07, p<.05)$, birth order $(r=.11, p<.01)$, having at least one chronic health condition $(r=.09, p<.01)$, relationship with the child with $\operatorname{SMID}(r=.37, p<.001)$, the family domain of the J-FES $(r=.19, p<.001)$, the service system domain of the J-FES $(r=.11, p<.01)$, the social/political domain of family empowerment $(r=.08, p<.05)$, the physical health component summary of the QoL of the primary family caregivers $(r=.09, p<.05)$, and the mental health component summary of the QoL of the primary family caregivers $(r=.14, p<.001)$ were statistically 
significantly and positively correlated with the $\mathrm{KINDL}^{\mathrm{R}}$ scores. The age of siblings $(r=-.20, p<.001)$

and their J-ZBI_8 scores $(r=-.13, p<.001)$ were statistically significantly and negatively correlated with the QoL of siblings of children with SMID $\left(\mathrm{KINDL}^{8}\right)$ scores.

Table 4 shows the factors associated with the $\mathrm{KINDL}^{\mathrm{R}}$ scores based on the findings of the multiple regression analysis. The following factors contributed to higher KINDL ${ }^{\mathrm{R}}$ scores: a more positive relationship with children with $\operatorname{SMID}(\beta=.38, p<.001)$, the younger age of siblings $(\beta=-.15, p$ $<.001)$, lower J-ZBI_8 scores $(\beta=-.10, p<.05)$, later birth order (i.e., younger siblings) $(\beta=.11, p$ $<.05)$, higher FA (J-FES) scores $(\beta=.10, p<.05)$, and female gender of siblings $(\beta=.09, p<.05)$ (adjusted $\left.R^{2}=0.22, F(6,480)=23.82, p<.001\right)$. Multicollinearity was not observed.

\section{DISCUSSION}

\subsection{Characteristics of the participants}

The total fertility rate in Japan is 1.43 (Ministry of Health, Labour and Welfare, 2018). Against the backdrop of a declining birthrate, in this study the average number of children in a family was higher than normal (2.75). Turning to the household income of the families, the average was 7.13 million yen (Ministry of Health, Labour and Welfare, 2017) in this study. The families were thus predominantly from the lower-income group, with $72.3 \%$ having an annual income of less than 7 million yen (Approximately US 6,396 dollars). The employment rate of women raising children who are between 
the ages of 7-17 in Japan is between $66.4 \%$ to $73.1 \%$ (Ministry of Health, Labour and Welfare, 2017);

thus, the employment rate of the primary caregivers in this study was much lower despite many of the women having children of a similar age. It is presumed that this led to lower household incomes than in ordinary households, since in families raising children with SMID, the employment of the primary caregiver is restricted due to the care needs of the children. Finally, with respect to the severity score of children with SMID in this study, the need for medical care was considered low overall, since $68.3 \%$ of the children scored under 10 points.

\subsubsection{QoL scores of siblings of children with SMID and their trends}

Several previous studies have reported that QoL tends to be low in siblings of children with a disease or disorder (Bowman et al., 2014; Marciano \& Scheuer, 2005; Rana \& Mishra, 2015). This study was undertaken under the assumption that similar results would be obtained for siblings of children with SMID.

In a survey of healthy elementary school students in Japan, the mean KINDL ${ }^{\mathrm{R}}$ score was 64.7 points (Shibata et al., 2003); in a study of healthy junior high school students, it was 60.9 points (Matsuzaki et al., 2007); and for elementary school students with mild developmental disabilities, it was 59.3 points (Furusho et al., 2006). However, the QoL scores of the siblings of children with SMID in this study were higher than those reported in these studies. Moreover, as in this study, a previous study reported high QoL of siblings of children with cystic fibrosis (Havermans et al., 2011). Most cystic 
fibrosis cases are diagnosed through neonatal screening. Considering the commonalities between

cystic fibrosis and the disabilities examined in the current study, we can infer that, as most of the children were known to have a disability since birth, their families had dealt with it over a long period of time. Unlike the onset of a sudden illness in a healthy child, family cohesion in the face of a disease and sufficient time to adapt to life with a sick child can be considered as likely reasons why the existence of a child with SMID did not result in a decline in the QoL of his or her siblings.

Moreover, since it has been reported that the presence of people with disabilities strengthens cohesion among family members and often encourages self-growth (Takano \& Okamoto, 2011), it can be presumed that the presence of children with SMID does not necessarily have a negative influence on any siblings. However, the present results should be generalized carefully in view of research participation bias. In other words, it is likely that the QoL score was high because the siblings likely to respond would tend to have a positive perception of children with SMID, the relationships among family members, and their life together.

In a previous study, self-esteem scores showed a higher trend in siblings of children with SMID than in healthy elementary and junior high school students (Matsuzaki et al., 2007; Shibata et al., 2003). It is likely that because they were living with siblings with SMID, the children unconsciously compared themselves to the children with SMID, which afforded them the opportunity to realize that health is of particular value. This may explain the siblings' higher self-esteem scores. 


\subsection{Factors affecting the QoL of siblings of children with SMID}

The results of this study indicated that the later birth order of siblings (i.e., younger siblings) is related to a higher QoL score, which supports the results of a previous study (Limbers \& Skipper, 2014). Moreover, the results indicated a trend of higher QoL scores for lower ages (more so in girls than in boys), in agreement with previous studies (Limbers \& Skipper, 2014; Matsuzaki et al., 2007; Shibata et al., 2003). It is likely that the parents do not talk much to younger siblings or those born later about the disease and the future of the child with SMID. Vermaes, van Susante, and van Bakel (2012) also suggested that parents may be less likely to disclose detailed information about the child's illness to younger siblings. It could be that less exposure to stressors related to the diseases and disorders of children with SMID in the family may have led to a higher QoL score. Indeed, younger siblings may have less capacity to notice stressors within the family caused by the diagnosis of a chronic health condition.

Relationships with children with SMID had the greatest influence on siblings' QoL in this study. Similar results have been reported in previous studies of patients and children with mental illness (Smith \& Greenberg, 2007). Previous studies have also reported that siblings of children with chronic illnesses were relied on to assume their parents' responsibility for their siblings (Abe \& Kawasumi, 2015). It is most likely that, having a good relationship with them, these children are actively involved in the care of a sibling with SMID. It is thus likely that the perception of playing an important role in 
the family resulted in improved QoL scores. These findings suggest that it is important for healthcare professionals to positively recognize that their siblings' age, birth order, and relationships with children with SMIDs are relevant to the quality of life of their siblings, and to support them as needed. It is important that healthcare professionals help these parents raise not only children with disabilities but also children with disabilities, including siblings. Specifically, it is necessary to help these parents, depending on the age and stage of development of their siblings, to spend time explaining or interacting with their siblings' children with disabilities.

Moreover, it was observed that QoL was also affected by the attributes of the primary caregiver in addition to those of the siblings themselves. Although no previous study reported that the nursing care burden experienced by the primary caregiver affects siblings' QoL, it was presumed that this may be due to a lack of psychological leeway to direct attention to the siblings as the nursing care burden increases. To prevent overburdening the primary caregiver, healthcare professionals should remain vigilant and facilitate cooperation among family members. Additionally, healthcare professionals are required to perceive the siblings as well as the primary caregiver as subjects for support and provide appropriate assistance based on an assessment of the care burden and living conditions of the whole family.

This study revealed that the higher score for the family domain of the FES was related to higher QoL scores of siblings. The family domain of the FES is an indicator of the ability of a family to 
respond to the problems involved in caring for children with disabilities at home (Koren, DeChillo, \& Friesen, 1992). It is presumed that if the primary caregiver of a child with SMID can handle the problems involved in rearing a child with a disorder at home, they can also respond well to the problems of siblings as needed. Parents play a core role in supporting the stable mental functioning of their children (Shibata, Nemoto, Matuzaki, \& Itabashi, 2013). These results therefore suggest that as the "family" is empowered, the siblings' QoL improves, and, based on this observation, it is likely that support from healthcare professionals to improve family empowerment may also be effective in improving siblings' QoL.

\subsection{Limitations of this study}

There were several limitations to this study. First, since the coefficient of determination of the model of factors affecting the QoL of siblings of children with SMID was .22, it cannot be concluded that the factors of the QoL of siblings were sufficiently elucidated. Other variables such as studies, club activities, and friendships may be assumed as important explanatory variables for sibling QOL. However, we considered the siblings as a member of a family caring for a child with severe motor and intellectual disabilities, and could not include these variables in the questionnaire. Second, because we used a cross-sectional survey design, we can only report on associations and not causality. Finally, the survey participation rate was $35.2 \%$ in this study. We therefore cannot rule out the possibility of selection bias. 
Several previous studies reported that QoL is affected by the coping behaviors of siblings (Rana \&

Mishra, 2015; Vieira \& Fernandes, 2013). We therefore deem it necessary for future studies to consider this behavior as a factor. It may be difficult to measure the QoL of siblings only in the context of caring for and living with children with SMID. As the siblings grow up, studies and club activities at school and relationships with friends become increasingly significant, especially in school-aged children. Such factors may affect the QoL of siblings of children with SMID. The relationships between individuals and family members' QoL appear to be quite complex, and such complexity needs to be clarified in future research.

\section{CONCLUSION}

The QoL of siblings of children with SMID was observed as showing a higher trend than that reported in previous studies with participants of a similar age. It was found that the factors affecting siblings' QoL were the relationships with children with SMID, the age of the sibling, the care burden of the primary caregiver, the score on the FA subscale of the FES, and the gender of the sibling. However, it cannot be concluded that the factors of siblings' QoL were sufficiently elucidated in this study, and therefore the coping behaviors of siblings should be considered in future studies.

Healthcare professionals need to support siblings during nursing visits. Moreover, our results suggested that positively supporting siblings' perceptions of their relationships with children with 
SMID, preventing the overburdening of the primary caregiver, and providing appropriate assistance related to the care of children with SMID based on assessments of the whole family's care burden and living conditions would help improve siblings' QoL.

\section{ACKNOWLEDGEMENTS}

This research was funded by the Grant-in-Aid for Challenging Exploratory Research from the Ministry of Education, Culture, Sports, Science, and Technology, Japan (15K15846 and 18H03093) (principal investigator for both: the name of one of the authors). We would like to express our thanks to Dr. Sato Naho (Chiba University) and Dr. Numaguchi Chieko (Tokiwa University) for their valuable advice. Furthermore, we are very grateful to all of the participants in this study. We would like to thank Editage (www.editage.com) for English language editing.

\section{CONTRIBUTIONS}

Study Design: R.W., H.F., K.N., A.M.

Data Collection: R.W., H.F., K.N.

Data Analysis: R.W., H.F., K.N., A.M.

Manuscript Writing and Confirmation: R.W., H.F., K.N., A.M. 


\section{REFERENCES}

Abe, M., \& Kawasumi, R. (2015). Practical study on the development of a support program for siblings of children with profound intellectual and multiple disabilities (PIMD) and their families. Annual Bulletin, Graduate School of Education, Tohoku University, 63(2), 141-166. Retrieved from http://hdl.handle.net/10097/60558. (in Japanese).

Arai, Y., Tamiya, N., \& Yano, E. (2003). The short version of the Japanese version of the Zarit Caregiver Burden Interview (J-ZBI_8): Its reliability and validity. Nippon Ronen Igakkai Zasshi [Japanese Journal of Geriatrics], 40(5), 497-503. doi:10.3143/geriatrics.40.497. (in Japanese).

Barrera, M., Atenafu, E., Nathan, P. C., Schulte, F., \& Hancock, K. (2018). Depression and quality of life in siblings of children with cancer after group intervention participation: A randomized control trial. Journal of Pediatric Psychology, 43(10), 1093-1103. doi: 10.1093/jpepsy/jsy040

Bertelli, M., Bianco, A., Rossi, M., Scuticchio, D., \& Brown, I. (2011). Relationship between individual quality of life and family quality of life for people with intellectual disability living in Italy. Journal of Intellectual Disability Research, 55(12), 1136-1150. doi: 10.1111/j.13652788.2011.01464.x.

Berbis, J., Oudin, C., Alessandrini, M., Vercasson, C., Barlogis, V., Chambost, H., \& Auquier, P. 
(2015). Quality of life in minor siblings of childhood leukemia survivors, long-term after diagnosis: A LEA study (for Leucemies de l'Enfant et de l'Adolescent — childhood and adolescent leukemia). Psychooncology, 24(6), 661-668. doi:10.1002/pon.3709

Baca, C. B., Vickrey, B. G., Hays, R. D., Vassar, S. D., \& Berg, A. T. (2010). Differences in child versus parent reports of the child's health-related quality of life in children with epilepsy and healthy siblings. Value Health, 13(6), 778-786. doi:10.1111/j.1524-4733.2010.00732.x

Bowman, S., Alvarez-Jimenez, M., Wade, D., Howie, L., \& McGorry, P. (2014). The impact of first episode psychosis on sibling quality of life. Social Psychiatry and Psychiatric Epidemiology, 49(7), 1071-1081. doi:10.1007/s00127-013-0817-5

Dambi, J. M., Jelsma, J., Mlambo, T., Chiwaridzo, M., Dangarembizi-Munambah, N., \& Corten, L. (2016). An evaluation of psychometric properties of caregiver burden outcome measures used in caregivers of children with cerebral palsy: A systematic review protocol. Systematic Reviews, 5(42), 1-6. doi: 10.1186/s13643-016-0219-3

Davey, H., Imms, C., \& Fossey, E. (2015). "Our child's significant disability shapes our lives": experiences of family social participation. Disability and Rehabilitation, 37(24), 2264-2271. doi: /10.3109/09638288.2015.1019013

Davis, E., Shelly, A., Waters, E., Boyd, R., Cook, K., Davern, M., \& Reddihough, D. (2010). The impact of caring for a child with cerebral palsy: Quality of life for mothers and fathers. Child: 
Care, Health and Development, 36(1), 63-73. doi:10.1111/j.1365-2214.2009.00989.x

Davis, K., Gavidia-Payne, S. (2009). The impact of child, family, and professional support characteristics on the quality of life in families of young children with disabilities. Journal of Intellectual and Developmental Disability, 34(2), 153-162.

doi: 10.1080/13668250902874608

Eladl, A., \& Atwa, H. (2011). Quality of life in siblings of autistic children. Pediatric Research, 70, 313. doi: $10.1038 / \mathrm{pr} .2011 .538$

Furusho, J., Kubagawa, T., Sato, H., Sibata, R., Nemoto, Y., Matsuzaki, K., ...Watanabe, S. (2006). Evaluation of quality of life scale for elementary school children with mild developmental disorder. No to Hattatsu, 38, 183-186. Retrieved from https://doi.org/10.11251/ojjscn1969.38.183. (in Japanese).

Gan, L. L., Lum, A., Wakefield, C. E., Nandakumar, B., \& Fardell, J. E. (2017). School experiences of siblings of children with chronic illness: A systematic literature review. Journal of Pediatric Nursing, 33, 23-32. doi: 10.1016/j.pedn.2016.11.007

Havermans, T., Wuytack, L., Deboel, J., Tijtgat, A., Malfroot, A., De Boeck, C., \& Proesmans, M. (2011). Siblings of children with cystic fibrosis: Quality of life and the impact of illness. Child: Care, Health and Development, 37(2), 252-260. doi:10.1111/j.13652214.2010.01165.x 
Houtzager, B. A., Grootenhuis, M. A., Caron, H. N., \& Last, B. F. (2005). Sibling self-report, parental proxies, and quality of life: The importance of multiple informants for siblings of a critically ill child. Pediatric Hematology and Oncology, 22(1), 25-40. doi:10.1080/08880010590896233

Ikeno, S., Takeda, J., Kuraishi, T., Otsuka, M., Ishikawa, H., \& Tatsuki, S. (1990). Theoretical and empirical study of the Olson circumplex model: Approach from the construct validation paradigm. Kwansei Gakuin Sociology Department Studies, 61, 83-122. (in Japanese).

Koren, P., DeChillo, N., \& Friesen, B. (1992). Measuring empowerment in families whose children have emotional disabilities: A brief questionnaire. Rehabilitation Psychology, 37, 305-321. doi:10.1037/h0079106

Limbers, C. A., \& Skipper, S. (2014). Health-related quality of life measurement in siblings of children with physical chronic illness: A systematic review. Families, Systems \& Health: The Journal of Collaborative Family Healthcare, 32(4), 408-415. doi:10.1037/fsh0000077

Marciano, A. R., \& Scheuer, C. I. (2005). Quality of life in siblings of autistic patients. Brazilian Journal of Psychiatry, 27(1), 67-69. doi:/S1516-44462005000100015

Matsuzaki, K., Namoto, Y., Shibata, R., Morita, K., Sato, H., Furusho, J., ...Maekawa, K. (2007). A study of the Kiddo-KINDL^${ }^{\wedge} \mathrm{R}$ (Questionnaire for Measuring Health-Related Quality of Life in Children, Revised Version for 13-to-16-year-olds) in Japan. The Journal of the Japan 
Pediatric Society, 111(11), 1404-1410. (in Japanese).

McPherson, M., Arango, P., Fox, H., Lauver, C., McManus, M., Newacheck, P. W., Perrin, J. M., Shonkoff, J. P., \& Strickland B. (1998). A new definition of children with special health care needs. Pediatrics, 102(1), 137-39. doi:10.1542/peds.102.1.137

Meadan, H., Stoner, J. B., \& Angell, M. E. (2010). Review of literature related to the social, emotional, and behavioral adjustment of siblings of individuals with autism spectrum disorder. Journal of Developmental and Physical Disabilities 22, 83-100. doi:10.1007/s10882-009-9171-7

Ministry of Health, Labour and Welfare. (2017). Comprehensive survey of living conditions. Retrieved from https://www.mhlw.go.jp/toukei/saikin/hw/k-tyosa/k-tyosa17/dl/10.pdf (in Japanese).

Ministry of Health, Labour and Welfare. (2018). Overview of demographic statistics. Retrieved from https:/www.mhlw.go.jp/toukei/saikin/hw/jinkou/kakutei17/dl/00_all.pdf (in Japanese).

Moyson, T., \& Roeyers, H (2011). The Quality of Life of Siblings of Children With Autism Spectrum Disorder. Exceptional Children 78(1), 41-55. doi: 10.1177/001440291107800103

Nishigaki, K., Yoneyama, A., Ishii, M., \& Kamibeppu, K. (2016). An investigation of factors related to the use of respite care services for children with severe motor and intellectual disabilities (SMID) living at home in Japan. Health \& Social Care in the Community, 25(2), 678-689.

Okada, K., Iai, M., Ishii, M., \& Ozawa, T. (2015). Habilitation manual for persons with SMID, severe motor and intellectual disabilities. Tokyo: Ishiyaku Publishers. (in Japanese). doi: 
$10.1111 /$ hsc. 12358

Okumura MJ, Van Cleave J, Gnanasekaran S, et al. (2009) Understanding factors associated with work loss for families caring for CSHCN. Pediatrics,124(4),392-398. doi: 10.1542/peds.2009-1255J.

Orsmond, G. I., \& Seltzer, M. M. (2017). Siblings of individuals with autism spectrum disorders across the life course. Mental Retardation and Developmental Disabilities Research Reviews, 13(4), $313-320$.

Raina P, O'Donnell M, Rosenbaum P, Brehaut J, Walter SD, Russell D, Swinton M, Zhu B, Wood E. (2005). The health and well-being of caregivers of children with cerebral palsy. Pediatrics, 115(6), 626-636. doi: 10.1542/peds.2004-1689

Rana, P., \& Mishra, D. (2015). Quality of life of unaffected siblings of children with chronic neurological disorders. Indian Journal of Pediatrics, 82(6), 545-548. doi:10.1007/s12098014-1672-4

Ravens-Sieberer, U., \& Bullinger, M. (1998). Assessing health-related quality of life in chronically ill children with the German KINDL: First psychometric and content analytical results. Quality of Life Research: An International Journal of Quality of Life Aspects of Treatment, Care and Rehabilitation, 7(5), 399-407. doi:10.1023/A:1008853819715

Schulte, F., Wurz, A., Reynolds, K., Strother, D., \& Dewey, D. (2016). Quality of life in survivors of 
pediatric cancer and their siblings: The consensus between parent-proxy and self-reports.

Pediatric Blood and Cancer, 63(4), 677-683. https://doi.org/10.1002/pbc.25868

Shibata, R., Nemoto, Y., Matuzaki, K., \& Itabashi, K. (2013). Characteristics of elementary school children with low QOL scores based on Kid-KINDLR questionnaire. The Journal of Child Health, 72(2), 274-281. Retrieved from https:/www.jschild.medall.net/Contents/private/cx3child/2013/007202/030/0274-0281.pdf (in Japanese).

Shibata, R., Nemoto, Y., Matsuzaki, K., Tanaka, D., Kawaguchi, T., \& Kanda, A. (2003). A study of the Kid-KINDL questionnaire for measuring quality of life in elementary school children in Japan. Journal of the Japan Pediatric Society, 107(11), 1514-1520. (in Japanese).

Smith, M. J., \& Greenberg, J. S. (2007). The effect of the quality of sibling relationships on the life satisfaction of adults with schizophrenia. Psychiatric Services, 58(9), 1222-1224. doi:10.1176/ps.2007.58.9.1222

Suzuki, Y., Takei, R., Takeuchi, N., Yamada, M., Morooka, M., Hiramoto, A., ...Ohno, Y. (2008). New scoring system for patients with severe motor and intellectual disabilities, medical care dependent group. Journal of Severe Motor and Intellectual Disabilities, 33(3), 303-309 (in Japanese).

Takano, Y., \& Okamoto, Y. (2011). A review and consideration of psychological studies on siblings of handicapped persons. Bulletin of the Graduate School of Education, Hiroshima University, 
60, 205-214. Retrieved from https://ir.lib.hiroshima-u.ac.jp/ja/00032176 (in Japanese).

Tokuda, Y., Okubo, T., Ohde, S., Jacobs, J., Takahashi, O., Omata, F., ...Fukui, T. (2009). Assessing items on the SF-8 Japanese Version for Health-Related Quality of Life: A psychometric analysis based on the Nominal Categories Model of Item Response Theory. Value in Health, 12(4), 568-573. doi.org/10.1111/j.1524-4733.2008.00449.x

Tokyo Metropolis. (2014). Support manual for children with severe motor and intellectual disabilities and home care for visiting nurses: For everyone to work on home care at ease. Tokyo: Tokyo Metropolitan Lifestyle and Cultural Affairs Bureau. (in Japanese).

Ushio, R. (2014). Quality of life of patients with severe motor and intellectual disabilities at home. Journal of Severe Motor and Intellectual Disabilities, 39(3), 441-446. (in Japanese).

Van Riper, M. (2003). The sibling experience of living with childhood chronic illness and disability. Annual Review of Nursing Research, 21, 279-302. doi:10.1891/0739-6686.21.1.279

Vermaes, I. P., van Susante, A. M., \& van Bakel, H. J. (2012). Psychological functioning of siblings in families of children with chronic health conditions: A meta-analysis. Journal of Pediatric Psychology, 37(2), 166-184. doi:10.1093/jpepsy/jsr081

Vieira, C. B., \& Fernandes, F. D. (2013). Quality of life of siblings of children included in the autism spectrum. Codas Jornal da Sociedade Brasileira de Fonoaudiologia, 25(2), 120-127. doi:10.1590/S2317-17822013000200006 
Wakimizu, R., Fujioka, H., Furuya, K., Iejima, A., \& Yoneyama, A. (2010). Development of the Japanese version of the family empowerment scale (J-FES). Journal of Health and Welfare

Wakimizu, R., Fujioka, H., Numaguchi, C., Nishigaki, K., \& Sato, N. (2015). Role recognitions of their own, role expectations for other family members, and support needs for the family empowerment of family members living with a child with severe motor and intellectual disabilities. International Nursing Care Research, 14(4), 1-10. (in Japanese).

Yılmaz, Ö., Türkeli, A., Karaca, Ö., \& Yüksel, H. (2017). Does having an asthmatic sibling affect the quality of life in children? The Turkish Journal of Pediatrics, 59(3), 274-280. doi:10.24953/turkjped.2017.03.007 
Table 1. Attributes of the sample $(n=789)$

\begin{tabular}{|c|c|c|}
\hline & $n /$ Mean $\pm S D$ & $\% /$ range \\
\hline \multicolumn{3}{|l|}{ Siblings } \\
\hline Current age (years) & $12.21 \pm 3.07$ & $6-18$ \\
\hline $6-12$ & 419 & 53.11 \\
\hline $13-18$ & 361 & 45.75 \\
\hline No answer & 9 & 1.14 \\
\hline \multicolumn{3}{|l|}{ Gender } \\
\hline Male & 365 & 46.26 \\
\hline Female & 413 & 52.34 \\
\hline No answer & 11 & 1.39 \\
\hline Number of siblings & $1.75 \pm 0.81$ & $1-6$ \\
\hline \multicolumn{3}{|l|}{ Birth order } \\
\hline First & 364 & 46.13 \\
\hline Second & 292 & 37.01 \\
\hline Third & 101 & 12.80 \\
\hline Fourth & 23 & 2.92 \\
\hline Fifth & 2 & 0.25 \\
\hline No answer & 7 & 0.89 \\
\hline \multicolumn{3}{|l|}{ At least one chronic health condition } \\
\hline Yes & 84 & 10.65 \\
\hline No & 705 & 89.35 \\
\hline \multicolumn{3}{|l|}{ Diagnosis (multiple answers allowed) } \\
\hline Atopic dermatitis & 34 & 4.31 \\
\hline Asthma & 31 & 3.93 \\
\hline Allergic rhinitis & 7 & 0.89 \\
\hline Heart disease & 4 & 0.51 \\
\hline Kidney disease & 3 & 0.38 \\
\hline Attention deficit hyperactivity disorder & 2 & 0.25 \\
\hline Nettle rash hives & 2 & 0.25 \\
\hline Epilepsy & 2 & 0.25 \\
\hline Cleft lip and cleft palate & 2 & 0.25 \\
\hline Type I diabetes mellitus & 1 & 0.13 \\
\hline Pervasive developmental disorder & 1 & 0.13 \\
\hline Turner syndrome & 1 & 0.13 \\
\hline Hydronephrosis & 1 & 0.13 \\
\hline Congenital myopathy & 1 & 0.13 \\
\hline Acute Lymphocytic Leukemia & 1 & 0.13 \\
\hline Spina bifida & 1 & 0.13 \\
\hline
\end{tabular}




\section{Primary caregiver}

Age (years)

20-29

$5 \quad 0.63$

30-39

172

21.80

40-49

541

68.57

$50-59$

58

7.35

$60-$

0.38

No answer

3

1.27

Gender

Male

60

7.60

Female

717

90.87

No answer

12

1.52

Education

Junior high school

2.28

High school

18

39.67

Junior college

313

10.65

College

84

25.98

University

205

16.35

Graduate school

129

1.01

Other

8

2.66

No answer

21

1.39

Marital status

Married

724

91.76

Single

53

6.72

No answer

12

1.52

Employment

Not working

404

51.20

Part-time

233

29.53

Full-time

129

16.35

No answer

23

2.92

\section{Children with SMID}

Age

$\begin{array}{cc}11.84 \pm 3.35 & 6-18 \\ 1.08 \pm 2.50 & 0-15 \\ 11.32 \pm 7.08 & 6-44\end{array}$

Age of onset

Severity score

$11.32 \pm 7.08$

6-44

Years of home care

Under 1 year

$16 \quad 2.03$

Over 1 and less than 2 years

$19 \quad 2.41$

Over 2 and less than 5 years

5.45

Over 5 and less than 10 years

43

28.77 

Over 10 years
371
47.02
No answer
113
14.32

\section{Family}

Household income per year (million yen) $\dagger$

Under 3 million yen

$117 \quad 14.83$

3-5 million yen

239

30.29

5-7 million yen

214

27.12

7-10 million yen

111

14.07

10-13 million yen

$39 \quad 4.94$

Over 13 million yen

16

2.03

No answer

53

6.72

$\dagger 1 \mathrm{USD}=122.87$ yen (at the time of the investigation); $S D=$ standard deviation. 
Table 2. Current status of KINDL, relationship with children with SMID, J-ZBI_8, J-FES, FACESKGIV-16, and SF-8

\begin{tabular}{lcccc}
\hline & No. of items & Mean $\pm S D$ & Score Range & Range \\
\hline Total scores of KINDL & 24 & $69.63 \pm 12.55$ & $0-100$ & $20.83-96.88$ \\
Physical health & 4 & $76.52 \pm 18.39$ & $0-100$ & $0-100$ \\
Affective well-being & 4 & $80.96 \pm 16.76$ & $0-100$ & $0-100$ \\
Self-esteem & 4 & $51.12 \pm 24.80$ & $0-100$ & $0-100$ \\
Family & 4 & $75.30 \pm 17.55$ & $0-100$ & $6.25-100$ \\
Friends & 4 & $78.06 \pm 17.73$ & $0-100$ & $0-100$ \\
& \multicolumn{2}{c}{}
\end{tabular}



School
Disease module $\dagger$
4

$$
57.02 \pm 15.33
$$
$0-100$
$6.25-100$
6
$76.19 \pm 16.56$
$0-100$
$0-100$

Relationship with children with SMID

3

$10.78 \pm 6.18$

$3-15$

$3-15$

J-ZBI_8

8

$8.33 \pm 6.24$

$0-32$

$0-32$

10

FA (J-FES)

12

$37.44 \pm 6.89$

$12-60$

$14-57$

SS (J-FES)

12

$39.42 \pm 6.93$

$12-60$

$16-58$

SP (J-FES)

10

$24.20 \pm 5.53$

$10-50$

$10-47$

Adaptability (FACESKGIV-16)

$8 \quad-0.73 \pm 2.30 \quad-8.0-8.0 \quad-8.0-7.5$

Cohesion (FACESKGIV-16)

8

$3.50 \pm 2.93$

$-8.0-8.0$

$-7.0-8.0$

PCS (SF-8)

$8 \quad 46.70 \pm 7.53 \quad 0-100$

$18.70-66.20$

MCS (SF-8)

$8 \quad 46.00 \pm 8.26$

$0-100$

$17.66-61.78$

$\dagger$ Siblings with at least one chronic condition (84 children) answered the disease module; $S D=$ standard deviation; KINDL measures QoL of siblings of children with SMID; J-ZBI_8 measures the primary caregiver's perceived burden of providing family care; J-FES measures the empowerment of the family; FA = family subscale; $\mathrm{SS}=$ service system subscale; $\mathrm{SP}=$ social/political subscale; FACESKGIV-16 measures family functioning; SF-8 measures health-related QoL in the primary caregiver; PCS = physical health component summary score; $\mathrm{MCS}=$ mental health component summary score. 
Table 3. Correlations for KINDL scores, attributes of the sample, J-ZBI_8, J-FES, FACESKGIV-16, and SF-8.

\begin{tabular}{|c|c|}
\hline & $\rho$ \\
\hline \multicolumn{2}{|l|}{ Siblings } \\
\hline Gender (1: Boy, 2: Girl) & $0.07 *$ \\
\hline Age & $-0.20 * * *$ \\
\hline Number of siblings & -0.01 \\
\hline Birth order & $0.11^{* *}$ \\
\hline At least one chronic health condition (1: Yes, 2: No) & $0.09 * *$ \\
\hline Relationship with children with SMID & $0.37 * * *$ \\
\hline \multicolumn{2}{|l|}{ Primary caregiver } \\
\hline Gender (1: Male, 2: Female) & 0.00 \\
\hline Age & -0.02 \\
\hline Employment (1: Not working, 2: Part-time, 3: Full-time) & -0.04 \\
\hline Marital status (1: Married, 2: Single) & 0.03 \\
\hline $\mathrm{J}-\mathrm{ZBI} \_8$ & $-0.13 * * *$ \\
\hline FA (J-FES) & $0.19 * * *$ \\
\hline SS (J-FES) & $0.11 * *$ \\
\hline SP (J-FES) & $0.08^{*}$ \\
\hline Adaptability (FACESKG4-16) & 0.01 \\
\hline Cohesion (FACESKG4-16) & 0.08 \\
\hline PCS (SF-8) & $0.09 *$ \\
\hline MCS (SF-8) & $0.14 * * *$ \\
\hline \multicolumn{2}{|l|}{ Children with SMID } \\
\hline Age & 0.02 \\
\hline Age of onset & 0.00 \\
\hline Severity score & 0.06 \\
\hline Years of home care & 0.07 \\
\hline \multicolumn{2}{|l|}{ Family } \\
\hline Household income per year & 0.03 \\
\hline
\end{tabular}

$*: p<0.05,{ }^{* *}: p<0.01,{ }^{* *}: p<0.001 ; \rho=$ the Spearman's rank correlation coefficient with total scores of KINDL; KINDL measures QoL of siblings of children with SMID; J-ZBI_8 measures the primary caregiver's perceived burden of providing family care; J-FES measures family empowerment; FA = family subscale; $\mathrm{SS}$ = service system subscale; $\mathrm{SP}$ = social/political subscale; FACESKGIV-16 measures family function; SF-8 measures health-related QoL in primary caregiver; $\mathrm{PCS}=$ physical health component summary score; $\mathrm{MCS}=$ mental health component summary score. 
Table 4. Associated factors of KINDL scores with siblings' QoL

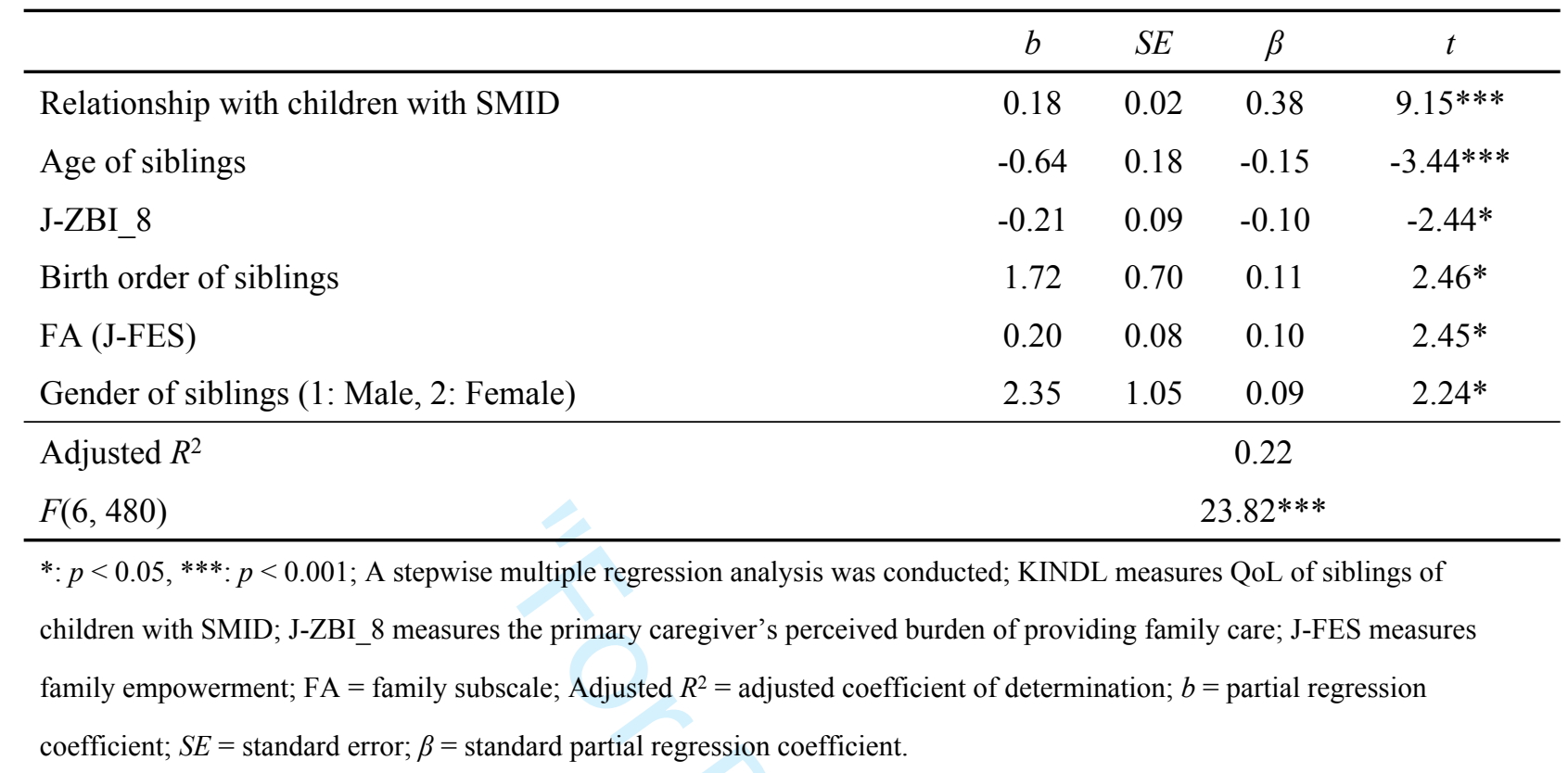

